\title{
DESVIO DE RIOS PARA A CONSTRUÇÃO DE BARRAGENS
}

\author{
Gabriel dos Santos Cruz Rocha \& Kikuo Tamada
}

RESUMO - As obras de desvio de rios para a construção de barragens, embora tenham caráter provisório, são de estrema importância, pois definem como o empreendimento será executado, garantindo segurança à sua construção, dentro de riscos calculados, devendo no entanto ser o mais econômica possível. As estruturas de desvio devem se encaixar no arranjo das estruturas permanentes, podendo ser utilizadas como tal. Este trabalho tem o intuito de apresentar as principais estruturas utilizadas em esquemas de desvio de rios e caracterizar sua utilização e aplicabilidade.

\begin{abstract}
Diversion works for dam construction are temporary. Nevertheless, they are extremely important, since they define how the construction is going to be made, and assuring its safety, within calculated risks. But, they have to be as economical as possible. The diversion structures must fit the global arrangement of the project, being in some cases be used as permanent structures. This document has the objective of present the main diversion structures used in diversion works schemes, as well as characterize their utilization and applicability.
\end{abstract}

Palavras-chave: desvio de rios; ensecadeiras; barragens; estruturas de desvio. 


\section{1 - INTRODUÇÃO}

Para a construção de obras nos leitos dos rios, via de regra é necessário fazer o desvio provisório do rio, no trecho de seu leito onde se pretende trabalhar, em especial para a construção de barragens.

Logo, o desvio tem a finalidade de realizar o manejo do rio, durante a construção do aproveitamento, através de estruturas de controle, que devem ensecar, proteger e garantir condições de trabalho na praça de construção da obra, de maneira segura, dentro de riscos aceitáveis.

A escolha do esquema de desvio a ser utilizado é muito importante para garantir a viabilidade econômica da obra como um todo. O esquema a ser adotado deve ser escolhido com base no balanço entre o custo das obras de desvio e o risco envolvido.

A complexidade e extensão das obras de desvio vão depender fundamentalmente do potencial de produção de cheias do rio. Se grandes cheias forem esperadas, as obras de desvio ganham grande importância, caso contrário, estas passam a ser mais simples e menos críticas.

Mas, o projeto do desvio deve ser considerado como parte do projeto como um todo, influenciando e sendo influenciado pelas demais estruturas da obra. As obras de desvio irão impactar principalmente no layout, no custo, no cronograma e na seqüência construtiva das estruturas permanentes.

Para a completa execução das obras das barragens é necessário que se divida o desvio do rio em fases. Em cada fase podem ser utilizadas diferentes estruturas, em localidades diversas. As estruturas utilizadas no desvio podem ser feitas exclusivamente para esta finalidade, mas também podem ser aproveitadas como estruturas permanentes, sendo incorporadas à obra principal.

As principais estruturas utilizadas no desvio de rios são:

- Ensecadeiras;

- Túneis;

- Canais;

- Galerias;

- Vertedouro com soleira rebaixada; e

- Circuito hidráulico de geração.

As ensecadeiras são as mais utilizadas para construção de barragens, uma vez que elas possibilitam a criação de uma área seca para a realização dos trabalhos no leito do rio. Existem diversos tipos de ensecadeiras que podem ser utilizadas, variando com o tipo de material utilizado, layout e método construtivo.

A combinação das diferentes estruturas em diferentes fases gera uma enorme gama de soluções, sendo que para cada caso particular de obra a ser implementada, ao menos uma alternativa deverá atender as necessidades peculiares à sua implantação.

Para a determinação e escolha do tipo de desvio de rio a ser utilizado em cada caso, diversos fatores devem ser levados em conta, incluindo aspectos físicos, técnicos e financeiros.

Cada vez mais se tem consciência da necessidade de se considerar os impactos ambientais na escolha do desvio de rio a ser implementado. O principal cuidado que deve ser tomado é com relação ao risco de geração de uma onda de cheia artificial a jusante da obra, no caso de falha das estruturas de desvio.

Uma obra de desvio de rio sempre tem associada a ela o risco de falha. Os riscos e os custos são fatores que estão diretamente relacionados. Para se diminuir os custos das obras de desvio, é comum assumir riscos maiores, pois quanto menor o risco, maior será o custo do desvio. Porém, em caso de falha, os prejuízos podem ser grandes, e portanto, riscos muito altos não são aconselháveis. O risco definido como aceitável determinará o período de retorno a ser utilizado no dimensionamento das estruturas de desvio.

Algumas análises de risco devem ser feitas, para se determinar qual nível de risco será aceitável. Para tanto, deve-se avaliar para o caso de falha, os prejuízos que serão acarretados nas obras em andamento e nas comunidades ribeirinhas a jusante da obra, os atrasos no cronograma e principalmente o risco de ocorrerem acidentes fatais com trabalhadores da obra ou moradores da 
região. Outros aspectos também devem ser avaliados, como por exemplo o aumento no custo do seguro da obra (muito usual na iniciativa privada) devido ao aumento do risco de falha do desvio.

Para obras de desvio em rios de médio e grande porte, para a construção de empreendimentos vultuosos, é essencial a utilização de modelo reduzido para ajudar na determinação do tipo de desvio a ser utilizado, e de suas características.

Apesar de seu custo significativo, o modelo reduzido sempre garante o retorno do investimento, seja pela economia acarretada pela otimização do projeto, seja pela mitigação dos riscos, ou ainda pela segurança que seus resultados trazem.

Uma das principais utilizações que se faz dos modelos reduzidos para as estruturas de desvio do rio é a determinação da metodologia de lançamento das ensecadeiras, podendo-se estabelecer a característica do material a ser utilizado e estimando-se o volume total a ser lançado, considerandose as perdas de material, devido ao arraste do mesmo pela água.

Modelos reduzidos também são muito importantes na verificação das características de projeto das estruturas, tais como altura das ensecadeiras, capacidade das estruturas de condução da água, sua localização e cotas de montante e jusante. $\mathrm{O}$ modelo ainda pode identificar problemas de erosão junto às estruturas, dentre outras inúmeras utilizações possíveis para o mesmo.

Com bastante freqüência, os modelos reduzidos podem levar a grandes alterações nos projetos de desvio, uma vez que são bastante precisos e aderentes ao protótipo, podendo-se por meio deles identificar elementos e fenômenos durante os ensaios que de outra maneira seriam de difícil previsão e pouca confiabilidade.

Outra fonte muito importante na definição da alternativa adequada e no dimensionamento dos projetos de desvio de rios é a experiência obtidas com a construção de obras já concluídas. Desta forma, é fundamental que se estudem casos similares ao da obra que se pretende construir, de maneira a aproveitar os sucessos e evitar falhas de soluções que foram utilizadas previamente. A experiência passada é fonte de conhecimento riquíssima e insubstituível.

Um ponto importante a ser ressaltado no projeto de desvio de rios é o julgamento pessoal da equipe de engenharia envolvida, que terá fundamental importância para o sucesso da obra de desvio, já que muitas decisões são tomadas com base subjetiva, como, por exemplo, o risco que será aceitável.

O objetivo final do projeto de desvio é a escolha da solução ótima, maximizando a eficiência e praticidade e minimizando custos e riscos de projeto.

\section{2 - ESTRUTURAS DE DESVIO DE RIO MAIS USUAIS}

Os desvios de rios são obras constituídas por estruturas capazes de fazer o manejo das águas do rio. Diversos tipos de estruturas de desvio podem ser utilizados, sendo muito comum a combinação de duas ou mais delas numa mesma fase do desvio. São inúmeras as combinações possíveis, sendo que para cada caso de rio a ser desviado, deve-se procurar uma solução ótima que atenda aos requisitos de segurança, da maneira mais econômica possível. Diferentes fases de desvio podem usar diferentes tipos de estruturas, ou estruturas semelhantes em posições e cotas diferentes.

As estruturas mais comumente utilizadas em obras de desvio de rios estão listadas a seguir:

- Ensecadeira;

- Túnel;

- Canal de desvio;

- Estreitamento do leito natural do rio;

- Galeria;

- Vertedor com soleira rebaixada; e

- Pelo circuito hidráulico de geração.

A estrutura mais usual que quase sempre está presente em obras de desvio de rios para a construção de barragens é a ensecadeira, que possibilita a criação de uma área seca para a execução dos trabalhos. 


\subsection{Ensecadeiras}

São barragens provisórias com a finalidade de fechar uma região do curso d'água, de forma a deixar seca uma área onde serão executados os trabalhos.

Apesar das ensecadeiras terem basicamente a mesma função de uma barragem, estas duas estruturas apresentam grandes diferenças entre elas. A referência 13 propõe que estas diferenças podem ser explicadas pelo fato das ensecadeiras terem uma vida útil menor e devido às condições de construção e operação das ensecadeiras.

A escolha e dimensionamento da ensecadeira dependem de fatores físicos, tais como a topografia, a geologia e a hidrologia, mas também dependem das características da obra a ser executada, podendo-se salientar como fatores determinantes os tipos de estruturas a serem utilizadas na obra (tipo de barragem, vertedor, casa de força), o cronograma da obra e os riscos aceitáveis. Porém, deve-se buscar sempre a solução mais econômica, dentro dos padrões de segurança aceitáveis e das boas práticas de engenharia.

As ensecadeiras em geral são constituídas de material disponível no local da obra. Os principais tipos de ensecadeiras utilizados em obras de desvio são:

- Enrocamento e terra (mais comuns);

- Celulares;

- Com cortina impermeável;

- Ensecadeira galgável; e

- Ensecadeira incorporada.

A ensecadeira deve ser dimensionada de forma a disponibilizar uma área ensecada que permita a execução das obras com adequada movimentação dos equipamentos e que confine as estruturas, conforme necessário.

O tipo e a forma da ensecadeira devem compatibilizar as características geológicas, hidrológicas e topográficas, respeitando os critérios hidráulicos. Desta forma, é definida a altura da ensecadeira, a necessidade de espigões para direcionar o fluxo e minimizar as erosões, e outras características.

Apesar da função básica da ensecadeira ser ensecar a praça de trabalho no leito do rio, um certo grau de infiltrações é admissível e via de regra irá ocorrer. A água que infiltrar deve ser bombeada para fora da praça de trabalho, sendo necessário prever bombas para a execução desta tarefa.

O conhecimento que se tem das condições do fundo do rio dificilmente é completo, uma vez que muitas vezes este é coberto por material de granulometria variável que estão constantemente se movimentando. Portanto, deve-se projetar a ensecadeira com uma certa margem de segurança, para que se evitem vazamentos excessivos e possíveis problemas de estabilidade na ensecadeira.

Além das condições de fundação, com o aumento da altura da ensecadeira fica mais difícil garantir a sua estanqueidade.

Como uma das maneiras de garantir a estanqueidade é aumentar a espessura das ensecadeiras, caso o dimensionamento não seja adequado, a ensecadeira poderá invadir a praça de trabalho, causando prejuízos à execução do empreendimento.

Logo, ensecadeiras onde as condições geológicas sejam pouco conhecidas ou ensecadeiras altas, devem ser dimensionadas com a devida folga.

Vale lembrar que a utilização de modelo reduzido é sempre recomendada para definir as características das ensecadeiras a serem utilizadas, principalmente em obras de médio e grande porte.

A foto apresentada na Figura 1 (Referência 14) mostra as ensecadeiras de montante e de jusante que desviaram o rio Canoas com o auxílio de túneis e mostra a região ensecada para a construção da barragem de Campos Novos. 


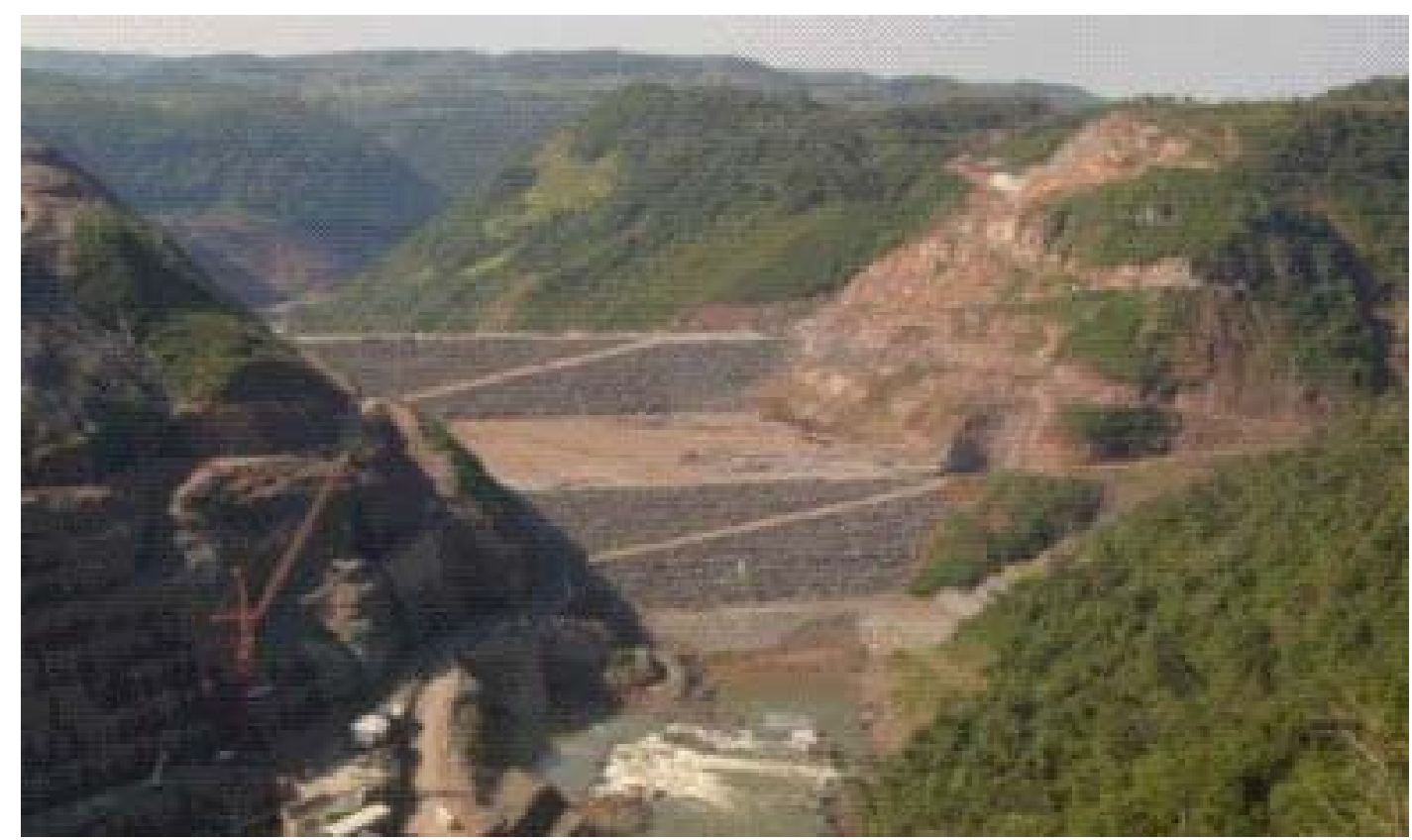

Figura 1 - $\quad$ Foto com a vista de jusante para montante das ensecadeiras para construção da barragem de enrocamento com face de concreto da UHE Campos Novos e a região ensecada por elas.

\subsubsection{Ensecadeira de Enrocamento com Terra}

As ensecadeiras de enrocamento com terra são as mais utilizadas já que em geral apresentam o custo mais baixo. O enrocamento é utilizado para fazer o fechamento do rio e proteger a impermeabilização. A terra (argila) é responsável pela estanqueidade da ensecadeira.

Em alguns casos pode-se dispensar o uso do enrocamento, mas somente quando as condições de escoamento permitem, ou seja, quando as velocidades são baixas. Entretanto, tem características muito similares a ensecadeira de enrocamento com terra. Portanto, como são menos freqüentes, este trabalho se ateve a descrever apenas as ensecadeiras de enrocamento com terra, mas podendo seu conteúdo ser aplicado, em sua maioria, às ensecadeiras apenas de terra.

As ensecadeiras de enrocamento com terra, são construídas a partir da execução da préensecadeira de fechamento do rio, que segundo a bibliografia 1 podem ser construídas principalmente de duas formas, que são, por "Ponta de Aterro" e "Em camadas". O primeiro tipo, pode apresentar duas formatações, por cordão simples ou por cordão duplo, conforme apresentado na Figura 2.

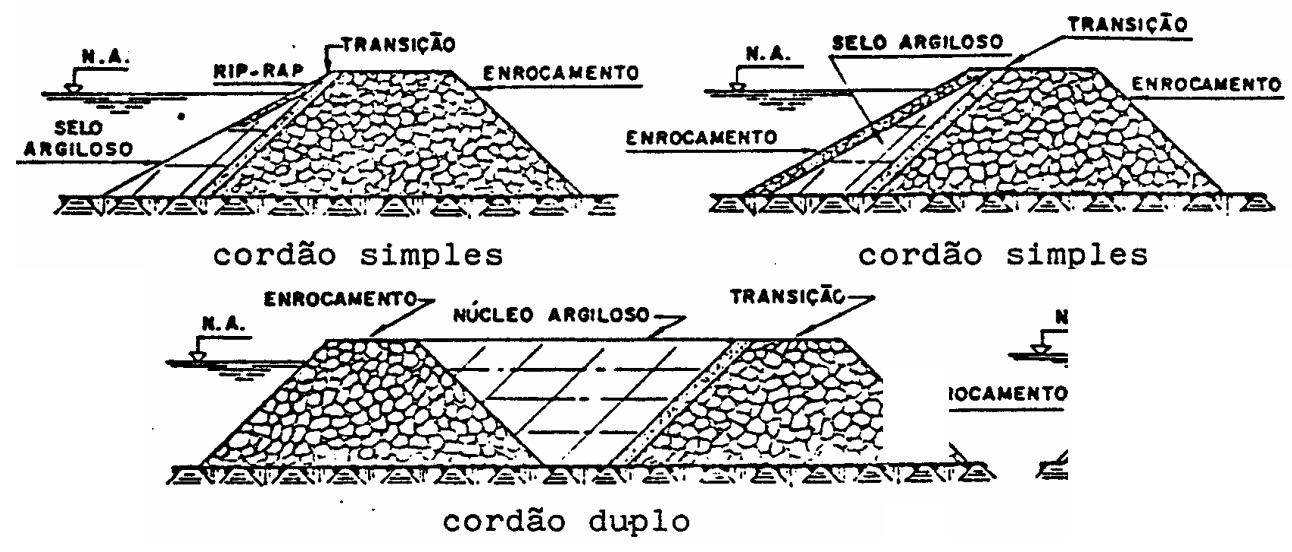

Figura 2 - Seção transversal típica de ensecadeiras de $\epsilon_{\text {mucamento com terra de cordão }}$ simples e de cordão duplo. 


\subsubsection{Ensecadeira com Cortina Impermeável}

A utilização de ensecadeiras com cortinas impermeáveis é necessária em alguns casos. A cortina impermeável ajuda na vedação da ensecadeira, reduzindo a infiltração ou percolação de água pelo corpo da ensecadeira ou pela base onde esta se apóia.

A estanqueidade da ensecadeira não é importante apenas para manter a praça de trabalho seca, mas também para garantir a estabilidade da ensecadeira, que pode sofrer grandes danos, no caso de uma vazão muito grande de água passar através de seu maciço.

Sua utilização é recomendada principalmente em três casos.

O primeiro quando da ocorrência de problemas no processo de impermeabilização da ensecadeira, podendo acarretar em infiltrações acima de níveis aceitáveis pelo corpo da ensecadeira.

O segundo quando o material de impermeabilização não for espesso o suficiente para impedir o fluxo de água, ou quando sua compactação não puder ser controlada, como em ensecadeiras de cordão duplo.

O terceiro caso onde se recomenda o uso de cortina impermeável é quando a ensecadeira está apoiada sobre uma camada grossa de material ruim, com alta permeabilidade, que facilitaria a passagem da água, podendo acarretar problemas de estabilidade da ensecadeira e de bombeamento excessivo para manter a praça de trabalho seca.

O primeiro caso tem um caráter principalmente corretivo, enquanto que, nos demais casos a utilização de cortina impermeável deve ser prevista desde a etapa de projeto.

Em todos os casos, o maciço da ensecadeira deve ser de material compatível com a utilização de cortinas impermeáveis, ou seja, deve ser de material fino. Estruturas de enrocamento inviabilizam a utilização de cortinas impermeáveis.

A cortina impermeável pode ser feita com diversos método e de diversos materiais. Alguns dos tipos possíveis são: injeções de calda de cimento, cut-offs, paredes diafragmas, mantas asfálticas e mantas de material plástico de alta densidade.

A figura 3 (Referência 8) mostra um esquema típico de ensecadeira com cortina impermeável.

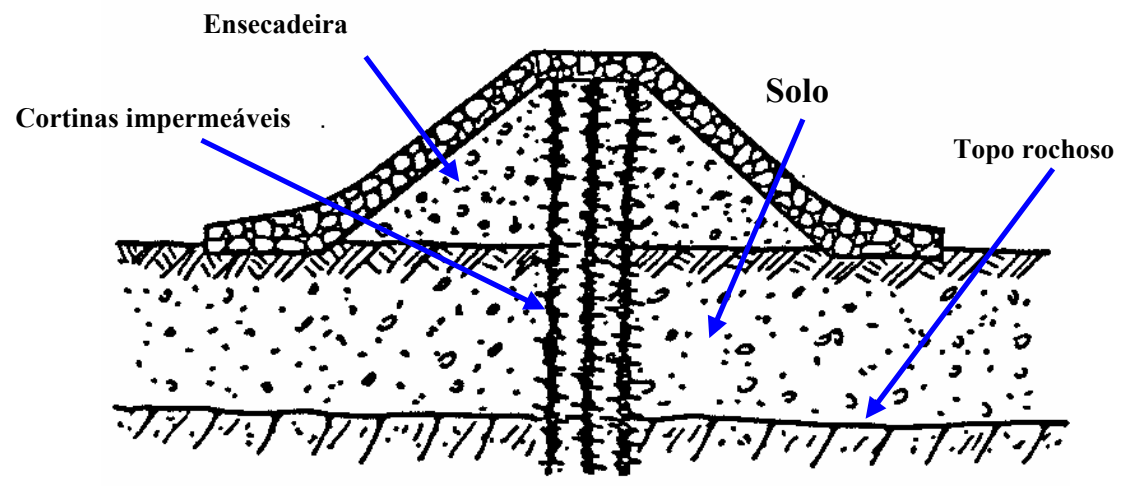

Figura 3 - Esquema típico de ensecadeira com cortina impermeável.

\subsubsection{Ensecadeira Galgável}

Uma das opções de arranjo de desvio do rio possível, é a que considera que as ensecadeiras podem ser galgadas durante o período de chuvas. A utilização deste tipo de concepção em geral é feita em situações onde os danos causados pelo galgamento da ensecadeira são aceitáveis.

A utilização de ensecadeira galgável é usual quando se tem vazão no período chuvoso bem superior a de estiagem, de forma que no período de estiagem o risco de galgamento seja baixo, possibilitando os trabalhos na região ensecada. Este tipo de comportamento hidrológico é comum 
em rios localizados em vales estreitos, e também nos rios da Amazônia, que aumentam muito sua vazão durante o período chuvoso.

Nos períodos com risco de galgamento, deve-se ter um plano de evacuação da área ensecada, de forma a proteger os operários e os equipamentos. Deve-se ainda prever, quando necessário, a realização de uma proteção para as estruturas principais que estão sendo executadas no leito do rio, de forma a minimizar os danos às mesmas.

A utilização de modelo reduzido torna-se fundamental para prever os efeitos do galgamento nas estruturas em construção e para dimensionar eventuais proteções das mesmas.

\subsubsection{Ensecadeira Incorporada}

Em algumas obras é possível incorporar a ensecadeira ao corpo da barragem principal.

Esta solução traz dois benefícios principais, o primeiro e mais importante é a redução do volume de aterro necessário e o segundo é evitar a necessidade de remoção da ensecadeira, quando ela não for mais necessária.

A utilização desta solução não é possível em qualquer situação. A sua viabilidade técnica é limitada pelo tipo de maciço da barragem principal e pelo tipo de ensecadeira utilizada, incluindo o material a ser usado e a forma construtiva da mesma.

As barragens onde são mais comuns a incorporarão da ensecadeira em seu maciço são quando estes são de terra ou de enrocamento, ou ainda variações destas, como por exemplo enrocamento com face de concreto e terra com enrocamento.

Nestes casos, o maciço da ensecadeira deve ser compatível com o maciço da barragem, para possibilitar sua incorporação. Ensecadeiras celulares ou de enrocamento com terra de duplo cordão não devem ser incorporadas à barragem.

Quando se opta por esta solução, o dimensionamento da ensecadeira e sua construção necessitam ser mais cuidadoso do que em casos onde a ensecadeira não é incorporada, pois a ensecadeira deixa de ter um caráter provisório, e passa a ser parte de uma estrutura permanente, apenas tendo sua construção feita num estágio inicial ao restante do maciço. Portanto, o material utilizado, a forma construtiva e o controle de qualidade devem atender aos mesmos padrões do restante da barragem.

\subsubsection{Ensecadeira Celular}

Consiste de estacas pranchas verticais encaixadas umas às outras formando cilindros (ou “células"), que são preenchidos com material solto. As estacas dão impermeabilidade e o material solto garante a estabilidade.

A ensecadeira celular é usualmente utilizada quando se tem pouco espaço no leito do rio para a execução de outros tipos de ensecadeiras, ou ainda quando se tem escassez ou falta de material impermeabilizante, como argila.

Em princípio, pode-se admitir, que o diâmetro da célula deve ser igual à altura da célula.

As ensecadeiras celulares podem ser formadas por uma série de células iguais ou por um conjunto de células denominadas células principais e células de ligação. As células principais têm formato cilíndrico, e são unidas umas as outras pelas células de ligação. A figura 4 mostra estes dois tipos de ensecadeira celulares.

Internamente à célula, existe do lado de montante hidráulico, um cordão de vedação, no contato com a base, de forma a reduzir as infiltrações. No lado de jusante, a célula contém um sistema de drenagem de água infiltrada. Em alguns casos, existe também um sistema de instrumentação na célula.

O principal problema que se pode ter com ensecadeiras celulares é a infiltração de água pela parte inferior da célula, no contato com o leito do rio. Portanto, devem-se tomar as devidas precauções, como retirada de solo inadequado e até concretagem de uma base para a ensecadeira. 
As ensecadeiras celulares podem ser construídas a seco, ou submersas. Em alguns casos, fazse uma pré ensecadeira para possibilitar a construção da ensecadeira celular a seco.

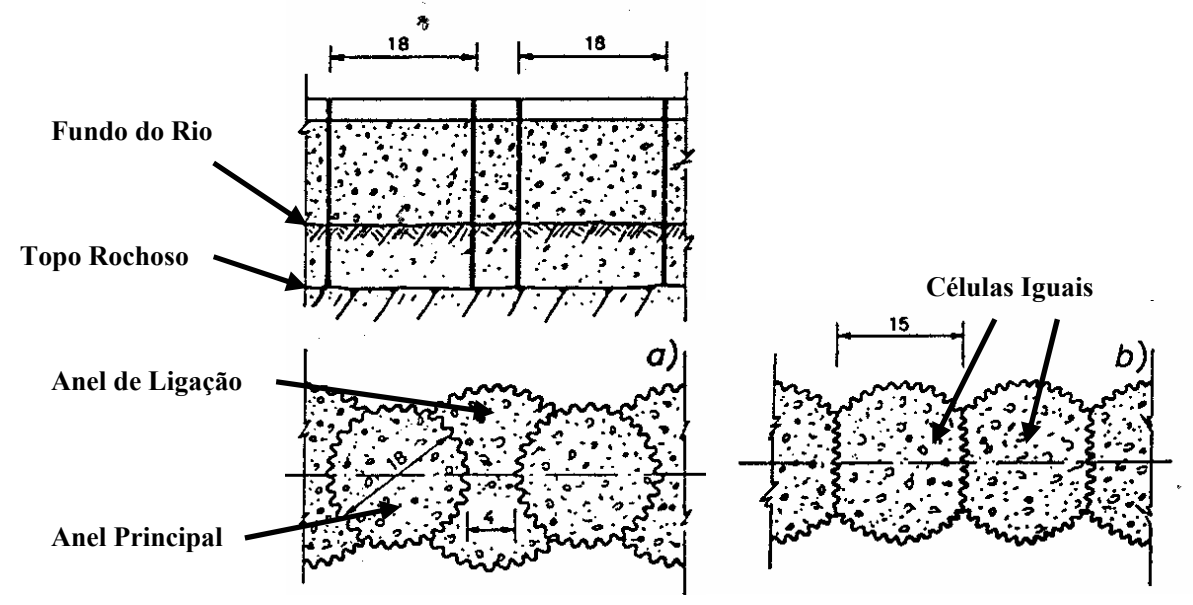

Figura 4 - Tipos de ensecadeira celular. a) perfil e vista superior de ensecadeira celular com célula de ligação. b) vista superior de ensecadeira celular com células iguais.

A seqüência de montagem das células deve ser estabelecida, respeitando-se a regra de que uma dada célula intermediária só deve ser feita após a conclusão do enchimento das duas células principais adjacentes, de forma a permitir o "estufamento" natural destas.

As ensecadeiras celulares podem ser reutilizadas após serem desmontadas. Isto pode significar uma redução nos custos com o desvio.

\subsection{Túneis}

Desvio de rios com a utilização de túneis apresentam de maneira geral configurações que seguem o esquema apresentado na figura 5. Conforme apresentado nesta figura, a utilização dos túneis via de regra está associada ao uso de ensecadeiras de montante e de jusante, que ensecam o leito do rio e desviam as águas para que estas passem pelos túneis. A utilização de túneis tem a vantagem de não interferir na construção da barragem e na escavação das demais estruturas. Porém, a viabilidade da utilização de túneis fica restringida a situações onde a topografia é de vales estreitos com rios encaixados. Isto se deve ao fato de ser uma solução mais cara e difícil de executar do que as demais opções possíveis para outras condições de terreno, tais como rio estrangulado por ensecadeira, canal lateral e por estruturas permanentes ou por galerias. Porém, em vales estreitos as demais alternativas se mostram inviáveis ou mais caras que por túneis, devido às condições topográficas, que nestes casos se mostram mais eficazes e interessantes.

A condição geológica das ombreiras do rio também limita o uso de túneis. Caso a rocha das ombreiras seja de qualidade muito ruim, o custo do túnel sobe muito e pode ser mais interessante realizar o desvio por galerias.

A qualidade da rocha também influencia no custo do túnel, uma vez que pode ser necessário revestir as paredes do túnel para garantir sua estabilidade. Além disso, quando a condição geológica é desfavorável e os túneis são feitos em rochas muito fraturadas ou em solo, a sua execução leva mais tempo.

Para possibilitar o desvio do rio por túnel, a sua construção deve ser iniciada o mais rápido possível. O desvio do rio só poderá ser feito quando o túnel e seu emboque estiverem prontos. 


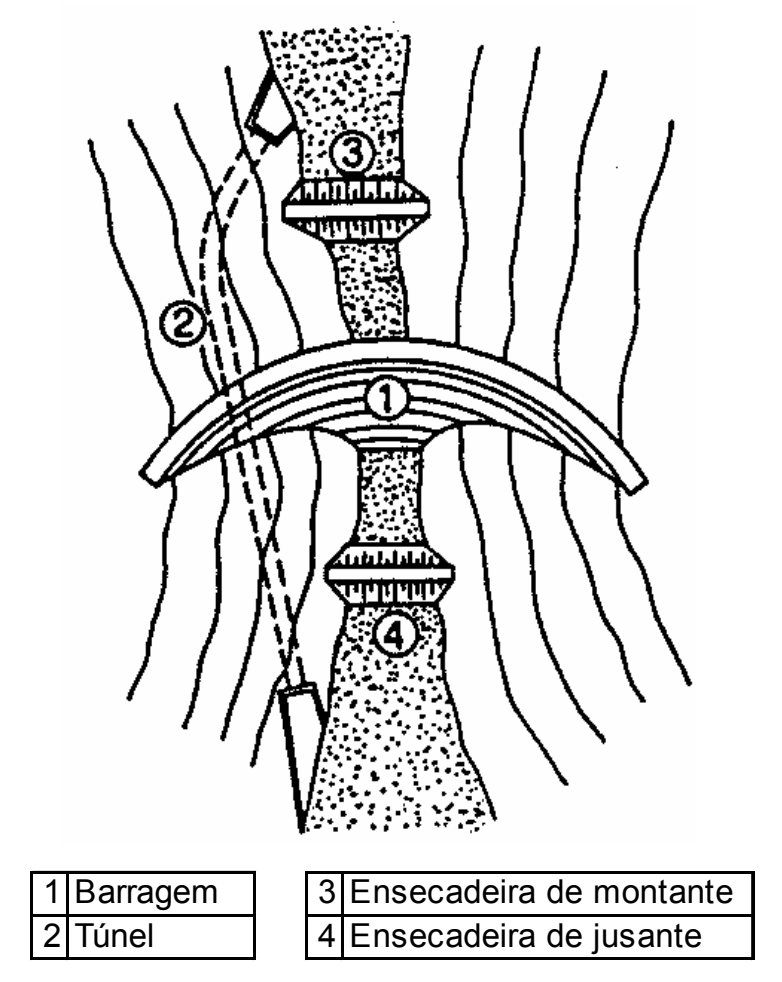

Figura 5 - $\quad$ Esquema de desvio por túneis.

A utilização de dois ou mais túneis também é interessante quando se pretende utilizar os túneis de desvio como parte de estrutura permanente da obra, tais como vertedores do tipo tulipa, descarregadores de fundo ou até mesmo no circuito hidráulico de geração, pois enquanto um túnel é convertido em estrutura permanente o outro continua desviando o rio.

A utilização dos túneis como estruturas permanentes pode tornar este tipo de solução de desvio mais atraente, uma vez que pode reduzir significativamente os custos da obra como um todo.

O fechamento dos túneis de desvio pode ser dividido em duas etapas. A primeira etapa é feita com o fechamento provisório dos túneis, com uso de comportas localizadas na estrutura de emboque do túnel (tomada d'água). A segunda etapa é o fechamento permanente do túnel pela execução do tampão de vedação.

Os túneis de desvio também podem ser utilizados para manter uma vazão mínima à jusante da barragem, durante o período de enchimento do reservatório. A manutenção da vazão sanitária tem o intuito de garantir a quantidade e a qualidade de água mínima necessária para as necessidades do meio biótico e de comunidades ribeirinhas à jusante do barramento, após o fechamento dos túneis de desvio e início do enchimento do reservatório.

Nem sempre é possível utilizar o túnel de desvio para este fim, sendo nestes casos necessária a construção de uma estrutura específica para tanto. Quando possível, a utilização do túnel de desvio pode trazer economia relevante, nos casos em que for utilizado com esta dupla finalidade.

Somente é possível a utilização de túneis de desvio para a descarga de vazão sanitária, se ao menos dois túneis estiverem operando, motivado pelo fato do sistema de descarga de vazão sanitária precisar estar concluído e operando antes que o reservatório inicie seu enchimento. Deste modo, o rio terá, a todo momento, um fluxo de água mínimo mantido à jusante do barramento.

\subsection{Canal de Desvio}

Canais para desvio temporário de rios são comumente utilizados em vales abertos, ou seja, de topografia suave. Quando o material das ombreiras é resistente à erosão, o uso de canais passa a ser ainda mais interessante. Pode-se escolher esta solução principalmente em dois casos. 
O primeiro seria a situação em que o rio é estrangulado por ensecadeiras e a seção estrangulada não tem capacidade suficiente de vazão para a cheia de projeto do desvio. Neste caso pode-se escavar as ombreiras para aumentar a seção de fluxo, ou até aprofundar o próprio leito do rio, conforme mostrado no esquema da figura 6.

O segundo caso refere-se à situação onde é necessário fechar completamente o leito do rio para a execução de estruturas permanentes, associado à condição de que a utilização de canais laterais ao leito do rio seja mais interessante que a solução de túneis ou galerias. Em geral, apenas quando as vazões são de magnitudes maiores é que a utilização de canais é viabilizada, caso contrário, o uso de galerias pode ser mais vantajoso. Neste caso, o esquema de desvio por canal lateral pode ser semelhante ao de túneis, tendo-se ensecadeira a montante e a jusante das obras, no leito do rio, possibilitando o desvio por esta estrutura. A figura 7 mostra um esquema típico de desvio por canal lateral de desvio, deste tipo.

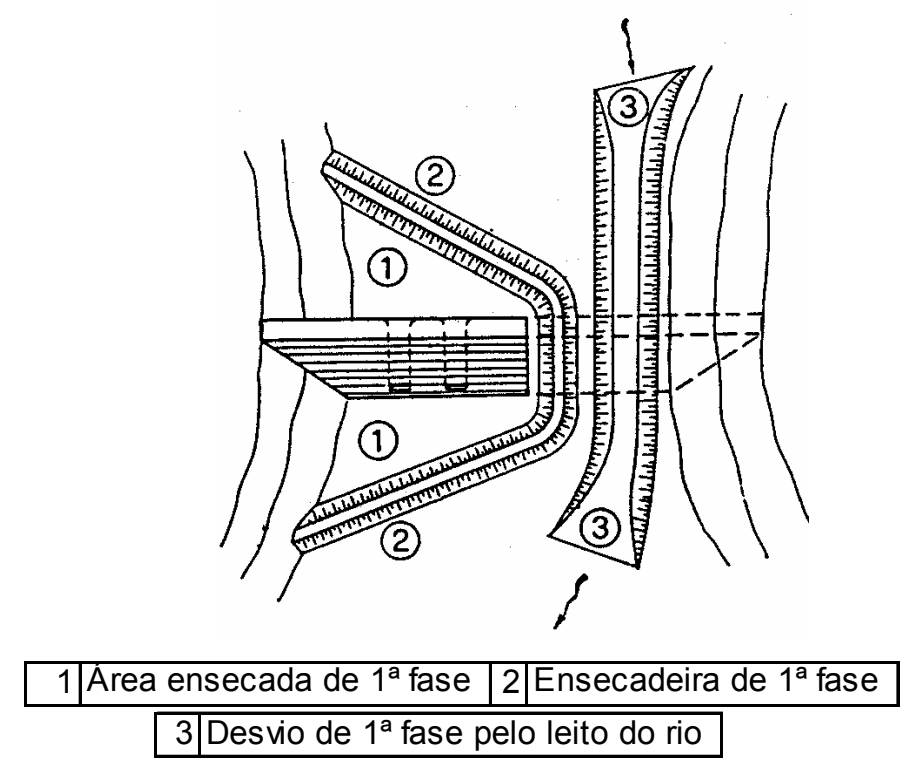

Figura 6 - Esquema de desvio de rio com aprofundamento da calha estrangulada.

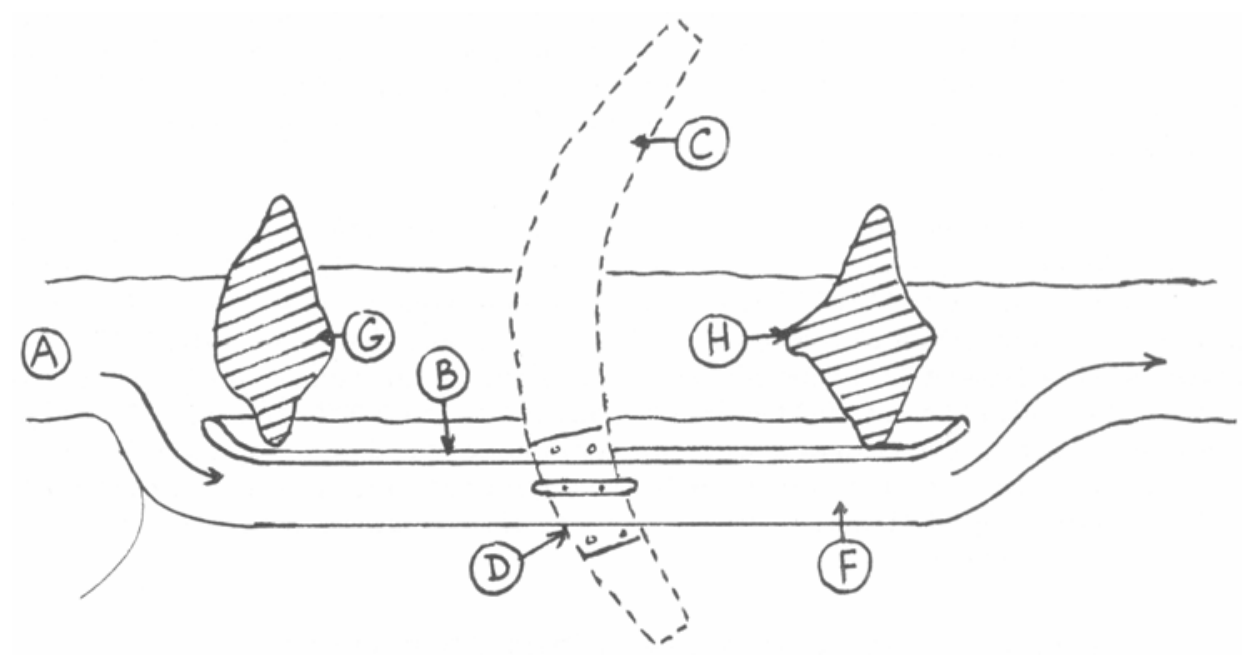

\begin{tabular}{|l|l|l|l|}
\hline \multicolumn{3}{|c|}{ LEGENDA } \\
\hline A & Fluxo & F & Canal \\
\hline B & Ensecadeira lateral & G & Ensecadeira de montante \\
\hline C & Barragem principal & H & Ensecadeira de jusante \\
\hline D & Aberturas temporárias & \multicolumn{2}{|c}{} \\
\cline { 1 - 2 } &
\end{tabular}

Figura 7 - Esquema típico de desvio por canal lateral. 


\subsection{Galerias}

Existem duas formas básicas de utilização de galerias para desvio de rio. O primeiro tipo é quando é utilizada de forma isolada e independente, funcionando como um túnel. O segundo tipo é quando a galeria é utilizada de forma associada com outra estrutura, sendo em geral construída embaixo da soleira dos vertedores.

Com o término da fase de desvio pelas adufas, após a conclusão das obras previstas para esta etapa de desvio, deve-se proceder com o fechamento das adufas.

A operação de fechamento pode ser complicada, principalmente com relação a estanqueidade, em especial no contato com o teto da galeria. Mas, também se deve considerar os custos para a realização do fechamento e as condições hidrológicas que possibilitem o fechamento.

O fechamento é similar ao realizado em túneis, sendo que primeiro é necessário realizar um fechamento provisório, por meio de comportas e ensecadeiras a montante e a jusante da galeria para depois executar o fechamento permanente por meio da concretagem das galerias localizadas no vertedor. $\mathrm{O}$ esquema de fechamento se assemelha muito também ao fechamento de desvio pela soleira rebaixada do vertedor, para a concretagem da ogiva do mesmo, mas no caso de galeria, há uma preocupação adicional, assim como nos túneis, com relação à estanqueidade do fechamento permanente.

O fechamento da galeria sob a ogiva do vertedor deve ainda dar acabamento à soleira do vertedor, na saída da galeria, de maneira a permitir um escoamento adequado sobre a soleira, durante a operação normal da usina.

\subsubsection{Galeria Independente ("Culverts")}

As galerias podem ser utilizadas de maneira isolada e independente de outras estruturas permanentes, realizando o desvio da mesma maneira que os túneis, e, na realidade, só se diferenciando destes pelo método construtivo, uma vez que o funcionamento hidráulico é igual para ambos.

O uso de túnel é mais freqüente, sendo que, normalmente, a utilização de galeria só é viabilizada em casos onde a topografia é plana ou quando as condições geológicas das ombreiras são inadequadas para a construção de túneis, ou seja, quando as margens são formadas de materiais como solos ou rochas ruins. Nos demais casos, o uso de túnel em geral é mais econômico.

As galerias, têm como principal desvantagem, em relação aos túneis, o fato de poder interferir nas obras das estruturas permanentes do empreendimento, em especial nas escavações das fundações e na interface da galeria com o maciço da barragem, principalmente na região impermeabilizante desta.

A galeria independente pode ser feita no leito do rio, localizando-se sob o maciço da barragem, ou pode ser feita na ombreira, podendo-se utilizar o método "cut and cover" para a sua execução.

As galerias isoladas, em geral, têm seção transversal retangular ou circular e são construídas com concreto armado, podendo ser constituída de elementos pré-moldados. A construção é feita em geral a seco, podendo ser necessário utilizar ensecadeiras para criar uma região de trabalho adequada e protegida para a sua execução. Quando ficam prontas, o rio pode ser desviado através delas.

Portanto, quando a galeria se situa no leito do rio, é usual realizar o desvio em duas etapas, sendo que na primeira o rio é estrangulado por ensecadeira, para a construção da galeria na região ensecada e na segunda fase o rio é desviado pelas galerias, de tal forma que ensecadeiras de montante e jusante de $2^{\mathrm{a}}$ fase são necessárias para ensecar a praça de trabalho no leito do rio e direcionar o fluxo pelas galerias. 
Quando a galeria se localiza na margem, pode-se fazer o desvio em uma única fase, construindo a ensecadeira a seco, sem interferência no fluxo do rio. Quando esta ficar pronta, o rio é fechado por ensecadeiras de montante e de jusante e é desviado por elas.

\subsubsection{Galeria Associada ao Vertedor (“Adufas”)}

O outro esquema possível para utilização de galerias de desvio é o uso destas de forma associada com estruturas permanentes da obra, sendo o mais comum a utilização conjunta com o vertedor. Neste caso, o vertedor é feito, deixando-se aberturas no seu maciço, para a passagem da água, devendo ser fechadas e concretadas para a operação normal do vertedor, após o término da etapa de desvio.

O uso deste tipo de galeria, quase sempre, só é possível em desvios constituídos por duas ou mais fases, onde na primeira fase o rio é desviado pelo leito estrangulado ou por canal lateral, permitindo a construção do vertedor com as galerias sob sua soleira, em região ensecada. Quando as obras do vertedor e das galerias estiverem concluídas, pode-se iniciar a segunda fase do desvio, realizando o fechamento do rio por ensecadeiras de montante e de jusante, desviando o fluxo do rio pelas galerias localizadas sob a soleira do vertedor.

Em alguns casos, pouco freqüentes, pode-se construir o vertedor e as galerias a seco, nas ombreiras, sem necessidade de prévio desvio do rio. Neste caso, pode-se fazer o desvio em uma única fase, contudo, além da condição topográfica, a utilização desta solução só será possível nos casos em que o cronograma da obra o permitir, já que as obras no leito do rio serão postergadas para após o inicio do desvio pelas galerias.

Este tipo de galeria é comumente chamado de "adufa".

\subsection{Vertedor de Soleira Rebaixada}

O vertedor é uma estrutura que é normalmente utilizada para o desvio do rio, em etapas avançadas de desvios de múltiplas fases.

Em casos onde a estrutura do vertedor é baixa, mas não o bastante para que o desvio seja feito pelo vertedor em sua cota final, pode-se manter um número adequado de vãos, ou um comprimento suficiente do vertedor livre com a soleira rebaixada para a realização do desvio do rio. Nestes casos, o vertedor funcionará como extravasor de soleira espessa. A figura 8 mostra um corte de um típico vertedor de soleira rebaixada para desvio de rio.

Esta forma de desvio é bastante simples, e tem a vantagem de utilizar a própria estrutura do vertedor, parcialmente construído, para realizar o desvio, em uma das fases da construção.

Entretanto, os vãos a serem utilizados para o desvio necessitam de algumas modificações em relação aos demais vãos, uma vez que é necessário realizar a concretagem final do vertedor e até mesmo a instalação das comportas de operação dos mesmos, em condições diferentes das disponíveis para os outros vãos.

Para possibilitar a concretagem do restante do vertedor, é necessário que os vãos sejam separados por muros que permitam que comportas do tipo stop-log possam interromper o fluxo de água em cada vão, de maneira a possibilitar os trabalhos em área seca e segura. Pode ser necessário utilizar comportas a montante e a jusante da soleira para ensecar a área a ser concretada. 


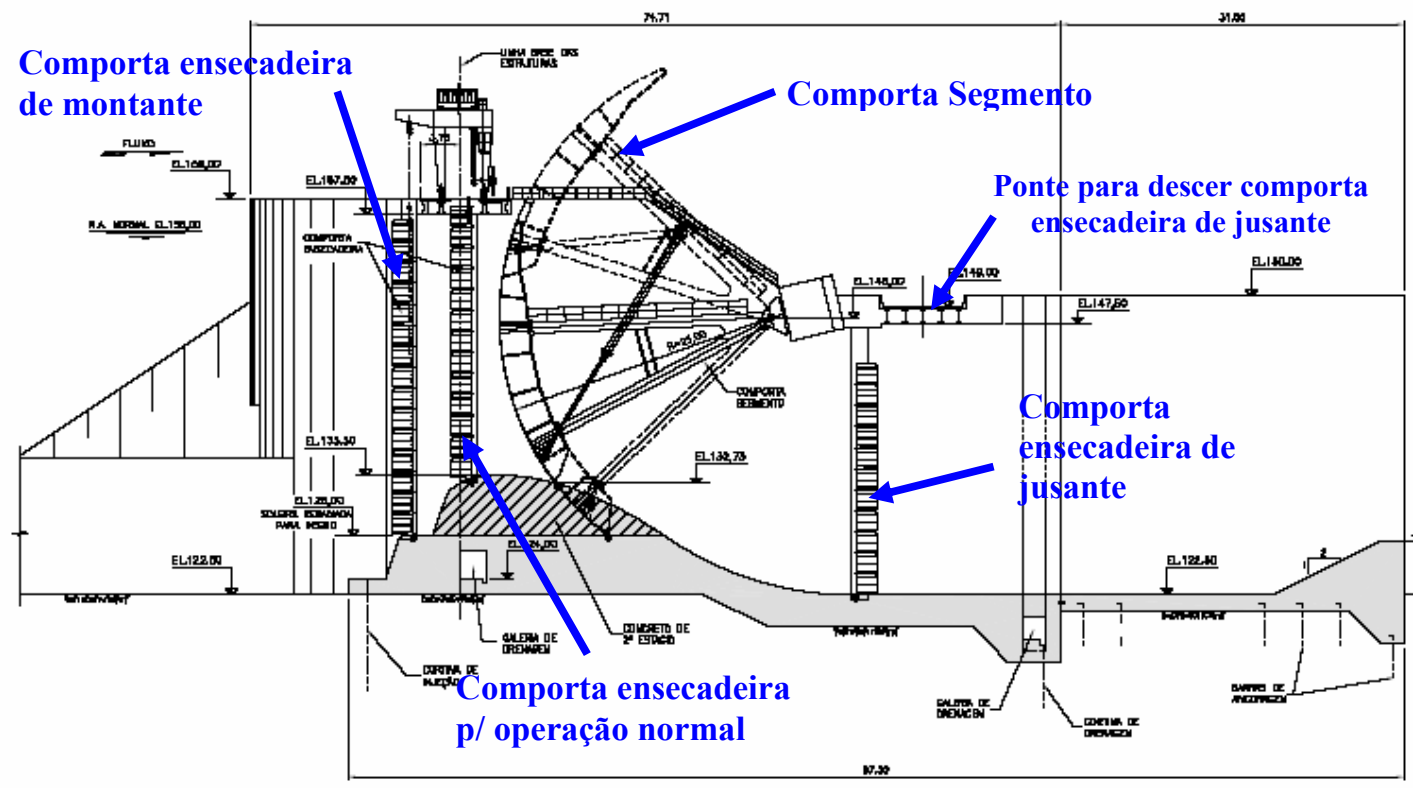

Figura 8 - Vertedor com soleira rebaixada do projeto básico da UHE Estreito. Corte típico.

\subsection{Desvio Pelo Circuito Hidráulico de Geração}

A utilização do circuito hidráulico de geração para desvio do rio não é uma prática freqüente em usinas de grande porte, sendo mais comum em usinas de baixa e média queda, assim como em micro e pequenas centrais hidroelétricas.

Em geral é utilizado na segunda etapa, ou em fases avançadas de esquemas de desvio de múltiplas fases.

É uma solução econômica, já que evita a construção de estruturas específicas para o desvio, entretanto se não forem tomados alguns cuidados, podem ser causados danos às estruturas permanentes destinadas à geração de energia.

As condições de escoamento durante o desvio são diferentes das condições de operação normal para geração, já que devido à ausência do rotor da turbina, as velocidades de escoamento são consideravelmente maiores durante o desvio.

Portanto, o tubo de sucção, a caixa espiral e o conduto forçado ficam sujeitos à cavitação e vibração, sendo estas as principais fontes de problemas neste tipo de alternativa.

Diversos estudos constataram que para se ter segurança na adoção desta solução, deve-se ter entrada suficiente de ar sob a tampa da turbina.

Os fabricantes de turbinas são geralmente contrários à utilização deste esquema de desvio, podendo acarretar perda ou limitação da garantia destes equipamentos.

Para se ter confiabilidade na adoção deste sistema de desvio, deve-se realizar estudos em modelo reduzido.

\section{FASES DOS DESVIOS DE RIOS}

Denomina-se fase de desvio toda vez que for provocada uma alteração no curso d'água.

O número de fases e suas características estão intimamente ligados a:

- Características da obra;

- Condições topográficas;

- Condições geológicas; e

- Cronograma da obra (plano de execução). 
De forma geral pode-se dizer que existem dois tipos de fases de desvio de rio. O primeiro tipo é o desvio feito em uma única fase e o segundo tipo é o desvio do rio feito em múltiplas fases.

O desvio em uma fase é comum em vales estreitos, onde previamente ao desvio são construídas estruturas para desviar o rio, tais como túneis, galerias ou canais laterais. Quando estas estruturas ficam prontas fecha-se o rio por meio de ensecadeiras a montante e a jusante do eixo do barramento, sendo o fluxo de água desviado pela estrutura construída previamente. Quando o reservatório puder iniciar seu enchimento fecha-se a estrutura de desvio, iniciando-se a fase de operação do empreendimento.

Já o desvio em múltiplas fases é normalmente utilizado em rios largos, com topografia abatida. O desvio se dá basicamente em duas fases, podendo ser necessário o uso de mais fases, caso existam restrições de prazo, ou para obras de grande vulto. A divisão do desvio se dá, em geral, com o rio sendo desviado na primeira fase pelo leito estrangulado do rio ou por canais laterais, sendo necessário o uso de ensecadeiras para fazer a condução do fluxo, e isolar a região onde serão construídas partes das estruturas permanentes da obra, devendo ser construída uma passagem para a água na fase seguinte, podendo ser utilizados galerias, vertedor com soleira rebaixada ou até o circuito hidráulico de geração. Uma vez que seja possível o desvio do rio pela estrutura de desvio da segunda fase, o rio é fechado, e passa a escoar por estas estruturas, iniciando a segunda fase de desvio. Variações desta solução geral podem acarretar na necessidade de fases adicionais.

\section{FATORES CONDICIONANTES NA ESCOLHA DO DESVIO DE RIO}

Diversos condicionantes influem na escolha do tipo de desvio do rio a ser utilizado, no número de fases de desvio e nas estruturas de desvio a serem utilizadas.

Os condicionantes podem ser separados em três tipos básicos: os físicos, os técnicos e os financeiros. Porém, estes fatores não podem ser avaliados separadamente, uma vez que existe uma forte interdependência entre eles.

Os principais fatores condicionantes que influem na determinação do desvio de um rio, conforme já listado anteriormente no Capítulo 1, estão apresentados abaixo:

- Aspectos físicos:

- Topografia;

Geologia;

Regime hidrológico e hidráulico; e

Localização.

- Aspectos técnicos:

- Características da obra principal:

- Arranjo geral;

- Cronograma da obra; e

- Métodos e materiais construtivos.

- Impacto sócio-ambiental;

- Experiência da projetista e da construtora;

- Reaproveitamento de equipamentos e estruturas de obras anteriores; e

- Risco de falha aceitável.

- Aspectos financeiros:

- Custos das obras.

Vale a pena salientar que os aspectos físicos vão influenciar a solução técnica a ser adotada, que por sua vez serão responsáveis pela definição dos custos das obras. Desta forma, fica claro e evidente que a dependência entre os diferentes fatores condicionantes deve ser respeitada e levada em consideração. 
A utilização de modelos hidráulicos em escala reduzida, tanto bidimensionais como tridimensionais é fundamental na determinação das características do projeto de desvio de rios.

Devido a grande eficácia da transmissão dos resultados obtidos em modelo reduzido para os protótipos, os primeiros ganham grande confiabilidade. Entretanto, este processo deve ser feito com muito critério e cuidado.

A grande maioria das características das estruturas de desvio projetadas em escritório devem ser verificadas e otimizadas nos modelos reduzidos.

Muitos problemas podem ser evitados com a utilização de modelos reduzidos, uma vez que nele podem ser identificados fenômenos de difícil previsão. Quando isto ocorre, podem ser sugeridas alterações para evitar ou reduzir os problemas, podendo-se monitorar as estruturas que possam estar sujeitas a problemas.

Pela simulação de diferentes fenômenos hidrológicos, o modelo possibilita a mitigação de riscos durante a construção.

Apesar de seu custo muitas vezes significativo, o modelo reduzido, via de regra, sempre se paga, seja pelo fato de mitigar os riscos ou seja pela otimização que o modelo proporciona. Por esta razão, a utilização de modelo reduzido é sempre aconselhável, podendo até ser considerado indispensável para obras de médio e grande porte.

\section{IMPACTOS SÓCIO-AMBIENTAIS}

É evidente que os principais impactos ambientais que um aproveitamento hídrico causa estão ligados à construção e operação das estruturas permanentes (barragem, vertedor, turbinas) e não dependem das obras de desvio do rio. Entretanto, a execução e operação das estruturas de desvio do rio para a construção de barragens também causam impactos ambientais, que apesar de serem de menor magnitude, importância e duração que os causados pelas obras principais, não são desprezíveis e devem ser levados em conta, podendo em alguns casos ter caráter irreversível.

Portanto, no momento da escolha da alternativa de desvio a ser adotada, deve-se considerar também os impactos ambientais que cada alternativa acarreta, pois diferentes soluções causam impactos ambientais distintos.

Todas as alternativas de desvio podem causar danos sérios à jusante em caso de falha. Isto também deve ser considerado, pois apesar deste impacto ser incerto (pode ou não ocorrer), porém, se ocorrer pode ser grave, com magnitude e importância altas.

\section{$7 \quad$ RISCOS}

Uma obra de desvio de rio sempre tem um risco de falha associado a ela. Isto significa dizer que os critérios adotados no projeto de desvio de rio tem o risco de não suportarem um possível evento de cheia que possa ocorrer durante cada etapa da construção.

Caso ocorra uma cheia superior à de projeto, serão causados danos tanto ao empreendimento em si (diretos), como danos a jusante da obra. Com isto, o empreendimento terá de arcar com os prejuízos diretos e indiretos para reparar os danos.

Em caso de colapso ou ruína das obras provisórias e/ou permanentes, serão ainda maiores os prejuízos, pois além de ter de reconstruir as obras afetadas resultando em atraso no cronograma, também poderá se formar uma onda artificial à jusante, que pode ter efeito devastador. Sérios danos podem ser causados ao meio ambiente e às comunidades e benfeitorias localizadas à jusante da obra.

Portanto, no momento de se definir qual o risco a ser considerado durante o andamento da obra, deve-se fazer uma estimativa dos prejuízos diretos e indiretos que uma eventual falha pode acarretar. 
Vale lembrar que conforme a obra vai evoluindo maior pode ser o prejuízo em caso de falha, uma vez que o empreendimento soma maior valor agregado. Por esta razão, é comum serem adotados riscos diferentes para fases de desvio distintas, podendo-se assumir riscos maiores no início da obra, durante a $1^{\text {a }}$ etapa de desvio do rio.

O risco assumido terá impacto direto no valor do seguro da obra, que via de regra é feito pelo empreendedor, pois quanto maior o risco, maior o valor a ser pago à seguradora. Entretanto, riscos maiores acarretam em vazões menores de desvio, ou seja, as estruturas de desvio serão menores e portanto mais econômicas.

Portanto, para se definir o risco que o empreendimento estará sujeito, em cada fase de desvio, deve-se fazer um balanço de custos, onde de um lado está o valor do seguro e os possíveis prejuízos em caso de falha, e do outro está o custo das obras de desvio. Deve ser feita uma análise financeira para diversos riscos, estimando seus custos, tentando definir qual a solução ótima, mas tendo-se sempre em vista o horizonte de estudo, ou seja, a vida útil das obras provisórias.

\section{CONCLUSÕES}

Este trabalho tentou abordar os principais tipos de desvio de rio utilizados para a construção de barragens, mostrando as principais estruturas utilizadas para este fim, sendo discutidas suas aplicabilidades e características.

A inclusão de casos reais de desvio, assim como de projetos que ainda não foram executados, foi utilizada para elucidar os pontos abordados, portanto, procurando-se mostrar quando cada tipo de solução pode e deve ser aplicada. seguintes:

Por tudo que foi apresentado, pode-se tirar algumas conclusões, podendo-se salientar as

- A solução de desvio a ser utilizada deve ser definida conjuntamente com o arranjo geral da obra, de maneira integrada, de forma a se obter uma solução harmônica para todo o empreendimento, que facilite a execução da obra e que permita que os trabalhos sejam executados com o máximo de segurança possível.

- Diversos fatores condicionam as características do sistema de desvio do rio, os principais são os condicionantes físicos, técnicos e econômicos. Estes fatores restringem a gama de opções que devem ser estudadas, até o ponto onde apenas uma solução pode ser considerada ótima para um determinado caso.

- Os desvios de rios se restringem a basicamente duas alternativas, que são desvio em uma única fase e desvio em múltiplas fases, sendo que o segundo geralmente tem duas fases. A utilização de fases adicionais é normalmente exigida por questões de cronograma de construção da obra.

- As ensecadeiras, via de regra são sempre utilizadas seja qual for o esquema de desvio adotado. Elas são fundamentais para permitir que as estruturas sejam construídas em local seco, protegendo a praça de trabalho do fluxo normal do rio, até a vazão máxima de projeto.

- A ensecadeira não serve apenas para isolar a praça de trabalho, também tem a função de direcionar o rio para escoar pela estrutura de desvio.

- O fechamento do rio é uma das operações mais complexas do desvio do rio, devendo ser estudado com cuidado. Pode ser feito basicamente de duas formas, ou em camadas ou por ponta de aterro.

- O desvio de rio é por definição um sistema provisório do empreendimento, podendo suas estruturas ser utilizadas apenas durante a construção da obra. Porém, soluções que diminuem a quantidade de estruturas provisórias se tornam mais atrativas. Ensecadeiras incorporadas e túneis de desvio utilizados como vertedor auxiliar são opções para reduzir o caráter provisório das estruturas de desvio, diminuindo os gastos com o desvio.

- O dimensionamento das estruturas de desvio depende basicamente do risco assumido como aceitável pelo projeto. Definido o risco, é possível calcular a cheia de projeto, que 
por sua vez vai definir as características das estruturas de desvio, tais como a altura da ensecadeira e as dimensões dos canais, galerias, túneis e outros.

- A capacidade de vazão das estruturas de desvio estão diretamente ligadas a altura da ensecadeira. Quanto mais alta for a ensecadeira, maior será a carga hidráulica e maior a capacidade de desvio das estruturas como túneis, galerias, canais e vertedor.

- Além disso, todos as características hidráulicas das estruturas e as características de escoamento do rio sendo desviado são fundamentais para o dimensionamento das estruturas de desvio.

- Para se ter uma solução otimizada e segura para o desvio de rio é fundamental utilizar modelos hidráulicos reduzidos. A utilização destes é muito importante na caracterização de diversos parâmetros do desvio e a verificação do funcionamento das estruturas.

- Com a crescente complexidade nos processos de licenciamento ambiental de empreendimentos como barragens e usinas hidrelétricas, cresce a importância da consideração dos efeitos que as obras causam ao meio ambiente, inclusive o esquema de desvio do rio. Portanto, devem ser buscadas soluções que acarretem no mínimo impacto possível, de forma a diminuir as dificuldades de o projeto ser aprovado ambientalmente.

\section{BIBLIOGRAFIA}

1) NAKAZATO, D. Alguns aspectos que influenciam a concepção e o projeto de desvios em rios. Dissertação de mestrado apresentada à EPUSP. São Paulo, 1988.

2) CURI, M.F.S. Fechamento do rio e estruturas normalmente utilizadas para o desvio. Dissertação de mestrado apresentada à EPUSP. São Paulo, 1986.

3) TAMADA, K. Galerias de desvio. In: SEMINÁRIO sobre DESVIO e MANEJO de RIOS, ABRH, São Paulo, SP. Maio 1991. 22p.

4) XXI SEMINÁRIO NACIONAL DE GRANDES BARRAGENS. Anais, Volume I. Rio de Janeiro, RJ. Dezembro 1994.

5) XX SEMINÁRIO NACIONAL DE GRANDES BARRAGENS. Anais. Curitiba, PR, Novembro 1992.

6) XIX SEMINÁRIO NACIONAL DE GRANDES BARRAGENS. Anais. Aracaju, SE, Março 1991.

7) SIMPÓSIO INTERNACIONAL SOBRE ARRANJOS GERAIS DE BARRAGENS EM VALES ESTREITOS. Anais. Rio de Janeiro, RJ, 1982.

8) TAMADA, K. Capítulo III - Desvio de rios. São Paulo.

9) XXII SEMINÁRIO NACIONAL DE GRANDES BARRAGENS. Anais. São Paulo, SP, Abril 1997.

10) XXIV SEMINÁRIO NACIONAL DE GRANDES BARRAGENS. Anais. Fortaleza, CE, Novembro 2001.

11) XXV SEMINÁRIO NACIONAL DE GRANDES BARRAGENS. Anais. Salvador, BA, Outubro 2003.

12) XXVI SEMINÁRIO NACIONAL DE GRANDES BARRAGENS. Anais. Goiânia, GO, Abril 2005.

13) ICOLD. River control during dam construction - Bulletin 48. Paris, 1984.

14) MEMÓRIA TÉCNICA CAMARGO CORRÊA. Fotos e desenhos das obras UHE Barra Grande, UHE Campos Novos e UHE Monte Claro. 2006. 